\section{HLA-B*5801 Should Be Used to Screen for Risk of Stevens-Johnson Syndrome in Family Members of Han Chinese Patients Commencing Allopurinol Therapy}

\section{To the Editor:}

Allopurinol is the major drug used in the treatment of gout and hyperuricemia. Generally, the drug is well tolerated, although a minority of people, about $2 \%$, develop a hypersensitivity reaction with rash or, less frequently, Stevens-Johnson syndrome (SJS) ${ }^{1}$. A multinational study reported that allopurinol is the most common drug associated with SJS and toxic epidermal necrolysis ${ }^{2}$. Genomic studies have shown that the HLA-B*5801 allele is a strong risk factor (OR 34-348) for developing allopurinol-induced $\mathrm{SJS}^{3,4,5,6,7,8}$. However, the clinical utility of HLA-B*5801 is unclear.

We conducted an observational study in the immediate family members of a male patient who experienced allopurinol-induced SJS in 1997 (index case). The patient, now 72 years old, was diagnosed with SJS by a dermatologist when he developed a generalized blistering rash, fever, and internal organ failure 1 week after the initiation of allopurinol $300 \mathrm{mg} /$ day for gouty arthritis. He had a white blood cell count of $13 \times 10^{9} / 1$ and $19 \%$ eosinophilia. Mild hepatic dysfunction and raised inflammatory markers (C-reactive protein $86 \mathrm{mg} / \mathrm{l}$ ) were observed. Skin biopsy excluded other blistering conditions and was consistent with SJS. Allopurinol was stopped and he was admitted to hospital but required transfer to the intensive care unit after 3 days. He was treated with topical glucocorticosteroids, oral prednisone $25 \mathrm{mg} /$ day, and cyclosporine. He was deemed well and discharged after 2 weeks.

Subsequently, the patient was recruited into our study of patients with allopurinol hypersensitivity ${ }^{9}$. He resides in Australia with his son and daughter. His other immediate family members, including a sister and brother, live in Malaysia. His brother also has gouty arthritis but has taken allopurinol $300 \mathrm{mg} /$ day for 10 years without any reactions. The other family members do not have gouty arthritis and do not take allopurinol.
The patient and his family members identify themselves as Han Chinese; his parents and grandparents were all born in China. The demographics and clinical information for the family are summarized in Table 1. HLA-B locus genotyping was performed using 4-digit, high-resolution DNA sequencing (from saliva samples) based on previous methods ${ }^{3}$. Laboratory technicians were blinded to the clinical status of the patients. The patient and his sister were HLA-B*5801-positive. By contrast, the allopurinol-tolerant brother and the son and daughter of the patient were HLA-B*5801-negative.

The cost-effectiveness of HLA-B*5801 for primary screening of potential allopurinol-induced SJS before initiation of the drug remains uncertain. Across studies thus far, all Han Chinese patients with allopurinol-induced SJS were found to be HLA-B*5801- positive ${ }^{3,7,9}$ (Table 2). However, HLA-B*5801 has a $20 \%$ carriage rate in Han Chinese ${ }^{3}$, meaning 1 in 5 Han Chinese patients starting allopurinol would be denied it if primary screening were applied. Consequently, a large number of patients would be left with limited options for gout management. Febuxostat, a newer xanthine oxidase inhibitor, is expensive and its longterm safety profile is not yet established ${ }^{10}$. Uricosuric drugs including probenecid and benzbromarone are less effective in renal impairment and may cause urate precipitation in renal tubules.

The clear influence of positivity for HLA-B*5801 on the phenotypical response to allopurinol exposure in a family is illustrated by the contrast between these 2 Han Chinese brothers who have gout. Also, by inference, the risk of developing allopurinol-induced SJS appears to be negligible in the children of the patient, whereas the sister is at high risk if allopurinol is commenced. HLA-B $* 5801$ should be used to screen Han Chinese patients for the risk of allopurinol-induced SJS prior to initiation of the drug, particularly if a family member has experienced this serious adverse reaction. Han Chinese patients with recurrent or tophaceous gout ought to have the option of HLA typing for the B*5801 locus when considering therapeutic decisions.

Table 1. Demographics of the index case patient (male) and immediate family members.

\begin{tabular}{|c|c|c|c|c|c|}
\hline & Birthdate & Current Medications & Comorbidities & Allergies & HLA-B $* 5801$ \\
\hline Patient & 1950 & Nifedepine, metoprolol & Gout, essential hypertension & None & Yes \\
\hline Brother & 1947 & $\begin{array}{l}\text { Felodipine, aspirin, allopurinol, } \\
\text { atorvastatin }\end{array}$ & Gout, essential hypertension & None & No \\
\hline Sister & 1956 & $\begin{array}{l}\text { Clopidogrel, irbesartan, atenolol, } \\
\text { amiodarone, amlodipine, atrovastatin }\end{array}$ & Essential hypertension & None & Yes \\
\hline Son & 1981 & Nil regular & None & Tetracyclines & No \\
\hline
\end{tabular}

Table 2. Summary of studies of HLA-B*5801 in allopurinol-induced Stevens-Johnson syndrome (SJS).

\begin{tabular}{lcccc}
\hline Study & $\begin{array}{c}\text { Allele Frequency of HLA-B*5801 } \\
\text { in Geographical Area of Study* } \\
\text { (ethnicity studied) }\end{array}$ & $\begin{array}{c}\text { HLA-B*5801- } \\
\text { Positive Rate in } \\
\text { Control Patients }\end{array}$ & $\begin{array}{c}\text { HLA-B*5801- } \\
\text { Positive Rate in } \\
\text { Patients with SJS, } \\
\text { TEN, or HS }\end{array}$ & OR (95\% CI) \\
\hline Taiwan 2005 & 0.15 (Han Chinese) & $20 / 135$ & $51 / 51$ & $580.3(34.4-9780.9)$ \\
Europe 2008 & 0.008 (Europeans) & NA & $15 / 27$ & $80(34-187)$ \\
Japan 2008 & 0.0061 (Japanese) & NA & $10 / 18$ & $62.8(21.2-185.8)$ \\
Thailand 2009 & 0.077 (Thai) & $7 / 54$ & $27 / 27$ & $348.3(19.2-6336.9)$ \\
Korea 2011 & NA & $41 / 432$ & $9 / 9$ & $179.24(10.19-3151.74)$ \\
Australia 2011 & 0.0490 (New South Wales white) & NA & NA \\
Hong Kong 2012 & 0.15 (Han Chinese) & $4 / 30$ & $19 / 19$ & $123.5(12.8-1195.1)$ \\
\hline
\end{tabular}

\footnotetext{
* Data from allelefrequencies.net if not available from original studies. TEN: toxic epidermal necrolysis; HS: drug-induced hypersensitivity; NA: data not
} available. 
MING-HAN HUGO LEE, MBBS (Hons); SOPHIE LENA STOCKER, BPharm, PhD; KENNETH MAPSON WILLIAMS, BSc (Hons 1), PhD; RICHARD OSBORNE DAY, MD, FRACP, Department of Clinical Pharmacology and Toxicology, St. Vincent's Hospital Sydney, Faculty of Medicine, University of New South Wales, Darlinghurst, New South Wales, Australia. Address correspondence to Dr. R.O. Day, Clinical Pharmacology, St. Vincent's Hospital Sydney, Darlinghurst, New South Wales 2010,Australia. E-mail: R.Day@unsw.edu.au Supported by Australian National Health and Medical Research Council Programme Grant 568612; Lexy Davies Bequest, St. Vincent's Hospital Sydney.

\section{ACKNOWLEDGMENT}

The authors acknowledge the family of the patient; for HLA typing, Associate Professor Elizabeth Phillips and Dr. David Nolan, Centre for Clinical Immunology and Biomedical Statistics and Department of Clinical Immunology and Immunogenetics, Royal Perth Hospital, Perth, Western Australia, Australia; for consultation and review of manuscript, Professor Garry Graham, Department of Clinical Pharmacology and Toxicology, St. Vincent's Hospital Sydney and Faculty of Medicine, University of New South Wales.

\section{REFERENCES}

1. McInnes GT, Lawson DH, Jick H. Acute adverse reactions attributed to allopurinol in hospitalised patients. Ann Rheum Dis 1981;40:245-9.

2. Mockenhaupt M, Viboud C, Dunant A, Naldi L, Halevy S, Bouwes Bavinck JN, et al. Stevens-Johnson syndrome and toxic epidermal necrolysis: Assessment of medication risks with emphasis on recently marketed drugs. The EuroSCAR-study. J Invest Dermatol 2008;128:35-44.

3. Hung SI, Chung WH, Liou LB, Chu CC, Lin M, Huang HP, et al. HLA-B*5801 allele as a genetic marker for severe cutaneous adverse reactions caused by allopurinol. Proc Natl Acad Sci USA 2005;102:4134-9.
4. Tohkin M, Kaniwa N, Saito Y, Sugiyama E, Hasegawa R, Aihara $\mathrm{M}$, et al. A whole-genome association study of major determinants for allopurinol-related Stevens-Johnson syndrome and toxic epidermal necrolysis in Japanese patients. Pharmacogenomics J 2011 Sep 13 [E-pub ahead of print].

5. Lonjou C, Borot N, Sekula P, Ledger N, Thomas L, Halevy S, et al. A European study of HLA-B in Stevens-Johnson syndrome and toxic epidermal necrolysis related to five high-risk drugs. Pharmacogenet Genomics 2008;18:99-107.

6. Tassaneeyakul W, Jantararoungtong T, Chen P, Lin PY, Tiamkao S, Khunarkornsiri U, et al. Strong association between HLA-B*5801 and allopurinol-induced Stevens-Johnson syndrome and toxic epidermal necrolysis in a Thai population. Pharmacogenet Genomics 2009;19:704-9.

7. Chiu ML, Hu M, Ng MH, Yeung CK, Chan JC, Chang MM, et al. Association between HLA-B*58:01 allele and severe cutaneous adverse reactions with allopurinol in Han Chinese in Hong Kong. Br J Dermatol 2012;167:44-9.

8. Kang HR, Jee YK, Kim YS, Lee CH, Jung JW, Kim SH, et al. Positive and negative associations of HLA class I alleles with allopurinol-induced SCARs in Koreans. Pharmacogenet Genomics 2011;21:303-7.

9. Lee MH, Stocker SL, Anderson J, Phillips EJ, Nolan D, Williams $\mathrm{KM}$, et al. Initiating allopurinol therapy: Do we need to know the patient's human leucocyte antigen status? Intern Med J 2012;42:411-6.

10. Love BL, Barrons R, Veverka A, Snider KM. Urate-lowering therapy for gout: focus on febuxostat. Pharmacotherapy 2010;30:594-608.

J Rheumatol 2013;40:1; doi:10.3899/jrheum.120803 